\title{
Influence of Opening Residential Quarters on Surrounding Traffic
}

\author{
Changrong Liu \\ North China Electric Power University (Baoding), Hebei, China \\ 657059780@qq.com
}

Keywords: Analytic hierarchy process, Branch density, Non-linear coefficient Intersection spacing, Vehicle flowrate, Average speed.

\begin{abstract}
This paper mainly studies the influence on the surrounding traffic after opening residential quarters. After studying the factors that influence traffic, we establish the evaluating indicator system and evaluation model. In this way, we can easily study the influence. Finally, we put forward the rationalization proposal for opening residential quarters.
\end{abstract}

\section{Introduction}

On February 21, 2016, the State Council issued Several Opinions on Further Strengthening the Administration of Urban Planning and Construction ${ }^{[1]}$.The sixteenth opinion is to promote the block system, no longer building closed residential quarters, and opening the residential quarters that has been built gradually. So studying the influence on the surrounding traffic is important after opening residential quarters. First, we establish the evaluating indicator system. Different weights are given to each evaluating indicator through analytic hierarchy process. Then, in the evaluation model, we regard the surrounding traffic of residential quarters as the target layer, select four important indicators as the criterion layer. Finally, we choose four roads of different areas as the program layer. This model helps us measure the surrounding traffic of any residential quarter that needs to be evaluated. We can easily study the influence through this model. We put forward the proposals for opening residential quarters in the end.

\section{Definitions and Assumptions}

\subsection{Definitions of Related Concepts}

- A closed residential quarter is a space that we can only consider the closeness of the inner road to the outside and ignore the interior planning.

- A open residential quarter is a space that the road inside is connected with the external thoroughfare after ensuring the normal working within it.

- After opening the closed residential quarter, the road inside becomes the urban branch.

\subsection{Assumptions of Ideal Conditions}

- The existing closed residential quarters all take the urban branch as boundary and occupy the whole area.

- The road inside the closed residential quarter is ring form or tree form.

The imagined pictures of a residential quarter before and after opening are as follows.

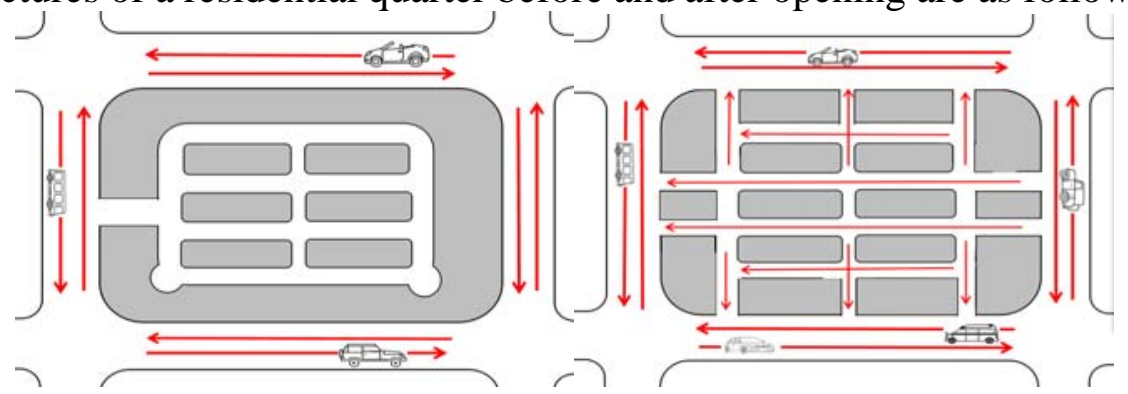

Fig. 1 the imagined pictures of a residential quarter before and after opening 


\section{Establish the Evaluating Indicator System}

A clear evaluating indicator system is necessary to evaluate the surrounding traffic of an open residential quarter. In addition, the evaluating indicator should reflect the level of traffic service, the scientific distribution of traffic resources and the coordination of traffic and traffic environment. Considering the above principles, the evaluating indicator system is established as follows:

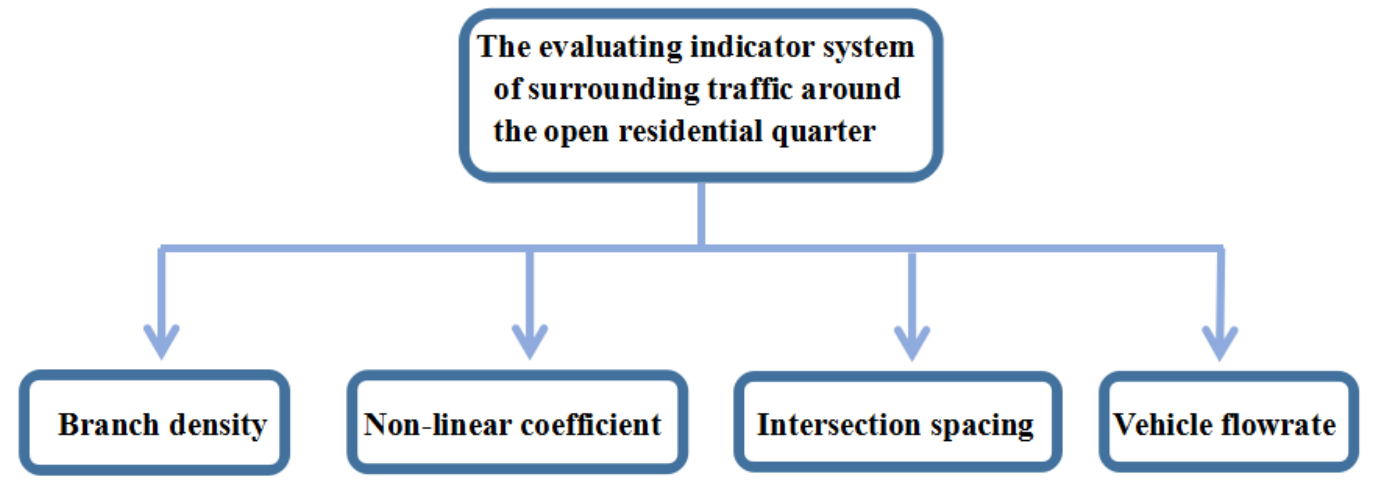

Fig. 2 The evaluating indicator system

- Branch density

The ratio of the number of inner branches to the total area of a residential quarter.

- Non-linear coefficient

The ratio of the actual distance to the straight-line distance between two points. According to the Code for Planning and Design of Urban Traffic (GB50220-95) ${ }^{[2]}$,the non-linear coefficient of public traffic lines should not be greater than 1.4, and the average non-linear coefficient of the whole line network should be 1.15 to 1.2 .

- Intersection spacing ${ }^{[3]}$

The intersection spacing represents the distance between adjacent intersections on one branch.

The experts represented by Professor Peikun Yang and Xunchu Xu believe that reducing the intersection spacing can achieve the effect of shunting traffic on main roads, and more successfully solve the problem of congestion. But the new entrances and exits can create new conflicts for vehicles. If the intersection spacing is increased, the vehicle can be driven more quickly, thereby solving traffic problems.

- Vehicle flowrate

Vehicle flowrate refers to the number of vehicles passed on a road within a given time frame. Before the residential quarter is opened, the vehicle flowrate is small, and the interference between vehicles is also small. After opening it, the vehicle flowrate will increase obviously, so the speed will decrease. Once the vehicle flowrate reaches the capacity of a road, more vehicles will lead to lower speed.

\section{Model of Vehicular Traffic}

\subsection{Determine the Weights of Evaluating Indicators}

The pairwise comparison matrices are determined according to reality, . So we can assign appropriate weights to different evaluating indicators.

Table 1. The weights of evaluating indicators

\begin{tabular}{c|c|c|c|c}
\hline \hline $\begin{array}{c}\text { Evaluating } \\
\text { indicator }\end{array}$ & Branch density & $\begin{array}{c}\text { Non-linear } \\
\text { coefficient }\end{array}$ & $\begin{array}{c}\text { Intersection } \\
\text { spacing }\end{array}$ & Vehicle flowrate \\
\hline Weight & 0.4621 & 0.0877 & 0.2938 & 0.1564 \\
\hline
\end{tabular}

\subsection{Select the Program Layer}

The "evaluation index system of urban traffic management" promulgated by the Ministry of Public Security of China in 2002 stipulates that the average speed of vehicles on the main road will be used 
to describe the traffic condition. Relevant regulations are as follows, and we give different scores to different traffic conditions.

Table 2. The relationship between traffic condition and average speed

\begin{tabular}{c|c|c|c|c}
\hline \hline $\begin{array}{c}\text { Traffic } \\
\text { condition }\end{array}$ & Light traffic & Mild congestion & Congestion & Severe congestion \\
\hline $\begin{array}{c}\text { Average } \\
\text { speed }\end{array}$ & $\begin{array}{c}\text { No less than } \\
30 \mathrm{~km} / \mathrm{h}\end{array}$ & $\begin{array}{c}\text { Less than } 30 \mathrm{~km} / \mathrm{h} \\
\text { \&greater than } 20 \mathrm{~km} / \mathrm{h}\end{array}$ & $\begin{array}{c}\text { Less than } 20 \mathrm{~km} / \mathrm{h} \\
\text { \& greater than } 10 \mathrm{~km} / \mathrm{h}\end{array}$ & Less than $10 \mathrm{~km} / \mathrm{h}$ \\
\hline Score & 8 & 6 & 4 & 2 \\
\hline
\end{tabular}

So the average speed is the only standard to measure traffic in the analysis process. By querying the average speed of roads in different areas, we select roads that represent the four levels (Label them 1 to 4).At the same time, we find the elevant data about these roads.

Table 3. Datas about the four roads

\begin{tabular}{c|c|c|c|c}
\hline \hline The number of roads & No.1 & No.2 & No.3 & No.4 \\
\hline Branch density $/ \mathrm{km}^{-2} \mathrm{~km}^{-2}$ & 3.94 & 2.88 & 2.16 & 2.35 \\
\hline Non-linear coefficient & 1.18 & 1.22 & 1.20 & 1.30 \\
\hline Intersection spacing/m & $400-500$ & $350-500$ & $300-450$ & $200-250$ \\
\hline Vehicle flowrate & little & less & many & a great many \\
\hline Average speed $/ \mathrm{km}^{-1} \mathrm{~h}^{-1}$ & 32.6 & 24.3 & 16.9 & 7.6 \\
\hline Score & 8 & 6 & 4 & 2 \\
\hline \hline
\end{tabular}

\subsection{Establish the Model of Vehicular Traffic}

The model of vehicular traffic can be established by analytic hierarchy process. In this model, we regard the surrounding traffic of residential quarters as the target layer, and regard the four evaluating indicator as the criterion layer. Finally, we take the four roads as the program layer. The model is as follows.

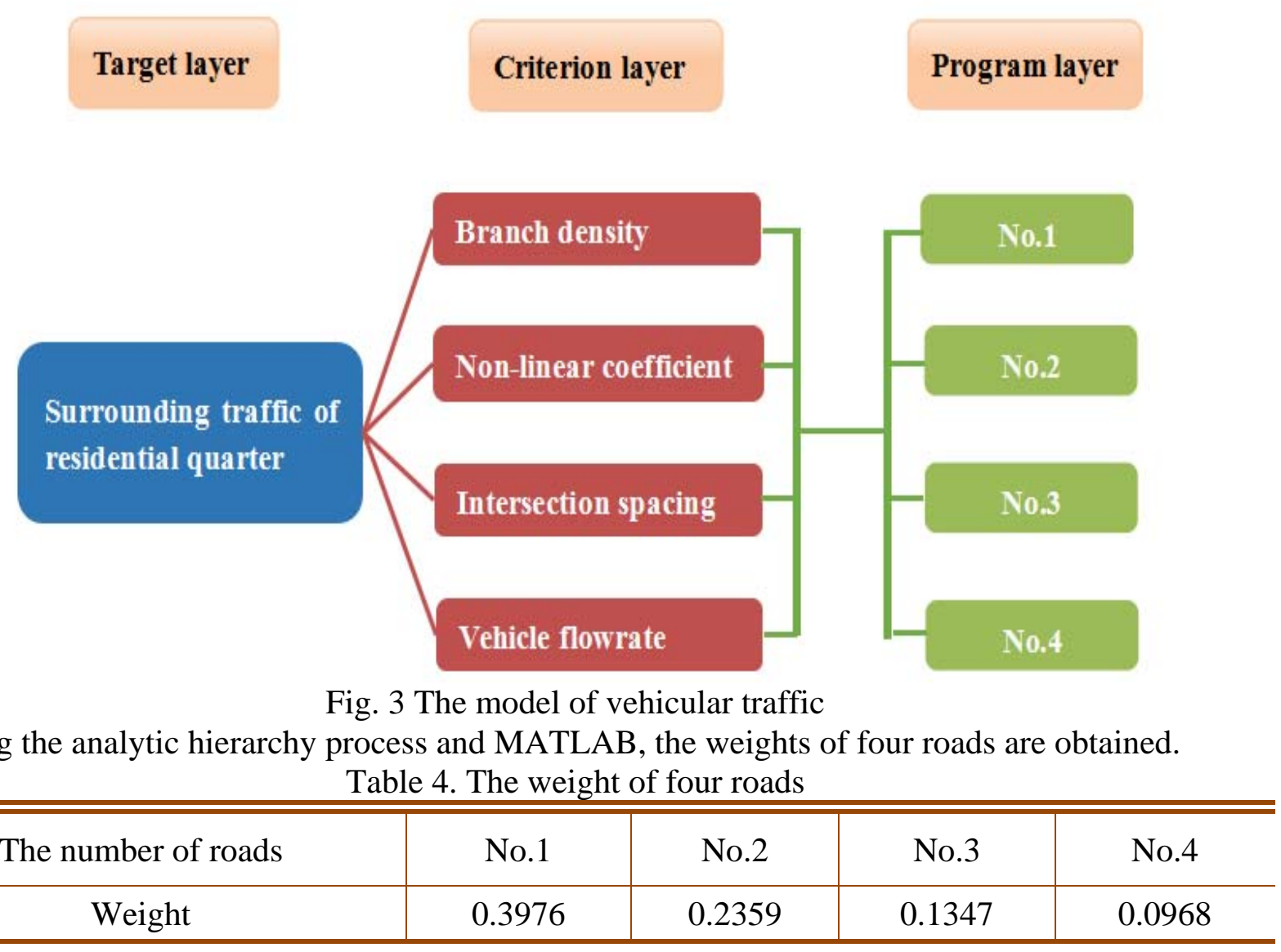




\subsection{Verify the Feasibility of The Model}

In the following example, we verify that the model can really evaluate the surrounding traffic of a residential quarter. We choose the road around a residential quarter of Haidian District as target layer, and look for data ${ }^{[5]}$ about four evaluating indicators before opening and after opening. Then, the weights are obtained by the model of vehicular traffic.

Table 5. The data about the residential quarter of Haidian District

\begin{tabular}{c|c|c|c|c|c|c}
\hline \hline & $\begin{array}{c}\text { Branch } \\
\text { density } \\
/ \mathrm{km} \cdot \mathrm{km}^{-2}\end{array}$ & $\begin{array}{c}\text { Non-linear } \\
\text { coefficient }\end{array}$ & $\begin{array}{c}\text { Intersection } \\
\text { spacing/m }\end{array}$ & $\begin{array}{c}\text { Vehicle } \\
\text { flowrate }\end{array}$ & $\begin{array}{c}\text { Average } \\
\text { speed/km } \mathrm{h}^{-1}\end{array}$ & Weight \\
\hline $\begin{array}{c}\text { Before } \\
\text { opening }\end{array}$ & 2.30 & 1.20 & 400 & many & 18.8 & 0.1351 \\
\hline $\begin{array}{c}\text { After } \\
\text { opening }\end{array}$ & 2.89 & 1.18 & 320 & $\begin{array}{c}\text { a great } \\
\text { many }\end{array}$ & 9.7 & 0.0992 \\
\hline
\end{tabular}

Compared with the weights of these four roads, the weight of the residential quarter before opening approximately equal to the weight of No.3,so it scores 4 points. The actual average speed is $18.8 \mathrm{~km}^{\mathrm{h}} \mathrm{h}^{-1}$, in line with the result calculated by the model. So the traffic condition in the residential quarter before opening is congestion. Same as the above analysis process, we can draw that the traffic condition in the residential quarter after opening is severe congestion. As the vehicle flowrate

Around this residential quarter is very large, it is obvious that the average speed decrease and the traffic condition get worse after opening. To sum up, the model of vehicular traffic is feasible and effective.

\section{Rationalization Proposal for Opening Residential Quarters}

- For the residential quarter with good surrounding traffic, it is not meaningful for relieving the traffic pressure to open it. At the same time, opening it results in waste of human and material resources. However, in order to facilitate the residents' travel, the relevant departments can open it to a small extent, according to its internal traffic condition.

- It is not suitable to open a residential quarter with poor surrounding traffic and large vehicle flowrate, because it is possible to create a counterforce to dredge the city traffic.

- For a residential quarter with irregular interior roads, such as some old districts without strict planning, we suggest that the internal roads should be linearized and regularized. In this way, opening residential quarter can greatly improve the surrounding traffic condition.

\section{Conclusion}

The model analyzes the datas roundly through analytic hierarchy process. It is of practical significance to study the influence of opening residential quarters on surrounding traffic according to this model. What is insufficient is that the model has idealized many factors. For example, ignore the destruction of the ecological environment caused by the opening of the residential quarter. In the future work, we will adopt a more comprehensive evaluation system and join the influence of soft environment, such as: policies, regulations, traffic lights, etc., in order to strengthen the credibility of the model.

\section{References}

[1]. Central Committee of the Communist Party of China, Several Opinions on Further Strengthening the Administration of Urban Planning and Construction, http://news.xinhuanet.com/politics/2016-02/21/c_1118109546.htm 
[2]. Ministry of Construction of the People's Republic of China, the Code for Planning and Design of Urban Traffic(GB50220-95),http://wenku.baidu.com/view/f3ae8e0ef78a6529647d535e.html

[3]. Zhi Li,The influence of intersection spacing on road traffic, Shanxi architecture, fortieth volume, twenty-sixth: 157-159,2014

[4]. Chen Xie, Study on dynamic model of congestion generation and propagation in urban traffic network, http://www.docin.com/p-859334426.html

[5]. Beijing Municipal Commission of Transportation, http://www.bjjtw.gov.cn/bmfw/jtz 